\title{
Analysis of Critical Thinking Skills Among Seventh Grade Students in the Solar System Topic through 5E Learning Cycle Model
}

\author{
Lena Lusiana $^{1}$, Munzil Munzil ${ }^{1 *}$, Erni Yulianti ${ }^{1}$ \\ ${ }^{1}$ Department of Science Education, Graduate Program, State University of Malang \\ *Corresponding author. Email: munzil.fmipa@um.ac.id
}

\begin{abstract}
Critical thinking is the result of reflective thinking, logical and focused on making decisions about an issue. The importance of critical thinking skills is evidenced by the incision between critical thinking indicators and competency targets in Permendikbud No. 21 of 2006. Critical thinking can be honed with Learning Cycle 5E with a constructivist approach that facilitates students to observe and research according to learning objectives. This type of research is the Mix Methods which aims to determine the effect of the 5E Learning Cycle in improving students' critical thinking on the material of the solar system. The study was conducted at Junior High School 1 Karangploso with class VII I samples determined through purposive sampling. The research instrument was developed by Radhiallah (2018) in the form of 28 items with 7 indicators of critical thinking. The results showed that: (1) learning the solar system by applying the Learning Cycle 5E model had an average percentage of $90.2 \%$ (very good) learning performance and (2) an increase in the critical thinking of Class VII I students on solar system material had an average of average d-effect of 3.42 (very high), so it can be concluded that students' critical thinking skills have increased significantly.
\end{abstract}

Keywords: Critical Thinking, Learning Cycle 5E, Solar System

\section{INTRODUCTION}

Natural Sciences (IPA) is the science that underlies the study of nature and all its contents. Science learning based on the analysis of natural phenomena around is still relatively low and needs to provide concepts to students, so they are not able to do the sensing and are far from everyday life experiences. The results of Widiantini's research (2017) show that the science competency of science students is still relatively low, thus proving that learning objectives have not been achieved. The development of students' knowledge in science learning can be through the analysis of life phenomena from various scientific perspectives in order to obtain the best solutions, so as to develop knowledge, attitudes and skills in accordance with the learning objectives.

Based on the results of preliminary observations made on science teachers at Junior High School 1 Karangploso on April 10, 2019, they stated that related to science learning related, among others, science teachers contribute to mathematics education and increase students' knowledge of solar system material on a daily basis. Initial observations made in class VII I and VII F look like learning done by the teacher and not so with students in every lesson, causing students to be inactive and need learning. The assignment of training assignments is not in accordance with the guidance, causing students to still be confused about the material and result in students' textual knowledge because they do not sensing the reality of life in the surrounding environment. The problem of science learning needs to be overcome by multidirectional learning and integrated with the environment (Wasiso, 2013).

Critical thinking is a form of reflective and logical thinking and focuses on the decisions that must be made (Ennis, 2011). The importance of critical thinking skills is evidenced by the incision between the indicators of critical thinking skills and the target competencies that students must achieve in Permendikbud No. 21 of 2006. The Indonesian curriculum currently assesses that one of the important goals in learning is the critical thinking skills (CBC) (Abdussalam, 2018).

The goals of critical thinking include proving, interpreting and finding solutions to a problem (Facione, 2013). The ability to think critically must be possessed by students in order to face various personal and social problems in their lives (Nuryanti, 2018). Students' critical thinking skills can support their problem solving abilities by expressing logical reasons for the problems faced (Nopia, et al. 2016).

Critical thinking skills can be honed with constructivist learning, one of them is Learning Cycle 5E. Ramadhani (2012) states that each learning model directs us into designing learning to help students in such a way that learning objectives are achieved. One innovative learning model that is able to facilitate students in constructing their own knowledge is learning by using the 5E Learning Cycle. Learning Cycle $5 \mathrm{E}$ is one of the complete constructivist models in the case of research-based learning or brainstorming used in the classroom (Campbell in Tuna \& 
Kacar, 2013). The results of the research Budiasih and Widiarti (2003) prove that the application of learning cycle learning can improve the quality of teaching and learning processes, both from quantitative and qualitative aspects.

Solar system material has characteristics that can be learned through sensing the events of daily life, such as the occurrence of day and night. Students are invited to connect experiences with the concepts of science that will be built, so students will feel that the concepts of science really occur in their surroundings. Problem solving activities through a good understanding of concepts can help students strengthen their thinking patterns and develop their thinking abilities (Yulianti, et al. 2018).

Problem solving is synonymous with authentic problems and material understanding. Students are gradually able to independently identify problems to provide experiences, so they are able to solve problems (Mahfuzah, 2018). One of the characteristics of someone who thinks critically is he always tries to find and explain the relationship between the problems faced with other relevant experiences (Saputra, 2016).

The $5 \mathrm{E}$ learning cycle learning model which is oriented to constructivism is very concerned with the students 'initial experience and knowledge and aims to improve students' understanding of concepts. In each phase of learning teachers are required to create learning conditions that move from science issues that are relevant to the student environment and provide opportunities for students to interact with others so that students can build their knowledge as a whole (Mabsuthoh, 2010).

The results of the study by Fajaroh and Dasna (2003) show that Learning Cycle 5E makes students more active, both in student observation and discussion activities and supporting the achievement of learning objectives. At the Learning Cycle 5E model stage, the learning process undertaken is no longer merely the transfer of knowledge from teacher to student, but the process of acquiring concepts oriented towards active student involvement in the learning process. Learning Cycle 5E emphasizes the role of students as the center of learning. Science concepts that have been constructed by students can benefit themselves, their biological and social environments (Poedjiadi, 2010). Based on the explanation above, this research needs to be held with the title "Analysis of Critical Thinking Ability of Class VII Middle School Students on Solar System Material through the 5E Learning Cycle Model".

Table 1 Percentage of Learning Execution

\section{METHODS}

This research is a Mix Methods research with Embedded Experimental Design type. This research uses one class sample. The population in this study were seventh grade students of the even semester of Junior High School 1 Karangploso in the 2018/2019 academic year with a sample of class VII I consisting of 32 students. The sampling technique in this study was purposive sampling. This study uses two instruments, namely: (1) measurement instruments using 28 items of pre-test and post-test multiple choice questions to measure critical thinking skills, observation sheets of learning implementation and interview instruments, (2) treatment instruments including syllabus, RPP and LKPD. Analysis of critical thinking skills using descriptive statistics, normality test using KolmogrovSmirnov, two tailed t-test, and d-effect size.

\section{RESULT AND DISCUSSIONS}

Data analysis of the results of initial observations aims to determine the learning model used at the school and to determine the characteristics of students. Preliminary observations made in class VII I and VII F show that learning is dominated by the teacher and does not involve students in each stage of learning. The questions given seem to refer more to the levels of $\mathrm{C} 1$ (remember) and $\mathrm{C} 2$ (understand).

Critical thinking instruments in this study use questions that have been developed by Radhiallah, et al. (2018) which has been validated with a reliability level of questions 81.13 (very high). The questions consist of 28 multiple choice questions with 7 indicators of critical thinking. The learning tools used in this study consisted of a syllabus and lesson plans that had been developed by Radhiallah, et al. (2018) which has been valid with reliability of 83.33 (very high).

In this study the learning activities of Learning Cycle 5E were carried out 5 times for learning and 2 times for pre-test and post-test. Each meeting was observed by one observer with the percentage of learning accomplishments in Table 1.1.

\begin{tabular}{|c|c|}
\hline Meeting to- & Skor (\%) \\
\hline I & 83 \\
\hline II & 87 \\
\hline III & 92 \\
\hline IV & 93 \\
\hline V & 96 \\
\hline Average & $\mathbf{9 0 , 2}$ \\
\hline
\end{tabular}


As an example, the third meeting was held on Monday 29 April 2019 with a time allocation of 3JP or 120 minutes adjusted to the RPP. Sub matter of the solar system at the first meeting namely the characteristics of the earth, earth's rotation, earth's revolution and its aftermath. Following is the description of learning activities with the 5 E Learning Cycle model in five stages.

\section{a) Engagement}

At the beginning of learning students observe Class VII BSE Science Books related to the shape of the earth and the rotation of the earth around the sun. Abdussalam's research results (2018) show that observing activities trigger students to see a phenomenon from a different perspective, so students will think more deeply, higher and more critical in interpreting the phenomenon. The Indonesian curriculum currently assesses that one important goal in learning is the critical thinking skill (CBC).

Students are required to convey the results of their observation orally then formulate questions with the group. The list of questions per group is written on the board so that all students can read, then two questions are selected that fit the learning objectives, namely determining the characteristics of the earth, analyzing the process of earth rotation and revolution and the events that result, and presenting a scheme of all-yearly motion.

Common questions raised by students are privately discussed with the group to get representative core questions with observed results. The selected questions have referred to critical thinking indicators, namely focusing questions, so learning refers to questions that have been linear with the learning objectives. The question is presentative of the reading and the picture presented, so that it can be seen that there is a student's curiosity about the material to be taught.

b) Exploration

At this stage students are required to think critically with indicators using established procedures, inference, record observations, report observations and make hypotheses and draw conclusions. Discussion in groups helps in the process of determining summary as an alternative solution to the problem by recording each opinion that develops from each group member. The teacher as a facilitator goes around to each group to monitor the process that is happening and check the truth of the concept. Educators try to invite students to simulate earth rotation and earth revolution that aims to make it easier to convey concepts that are difficult to present directly during learning activities and also material that is abstract, such as material about the solar system (Abdussalam, et al. 2018).

\section{c) Explanation}

At the beginning of the explanation phase, students work on discussion questions related to experiments that have been conducted with their groups accompanied by evidence from gathering information from several sources. The presentation of the results of the discussion was represented by group 4 to get responses, suggestions and questions from other groups.

Students try to provide clarification of their explanations, so definitions and explanations of concepts are discussed based on student explanations as a basis for discussion. Students perform activities in accordance with indicators of critical thinking, namely discussion and presentation with good grammar and are sensitive to mistakes.

d) Elaboration

This stage students try to do the exercises to apply the skills and concepts by working on five questions as exercises. This can make students able to elaborate knowledge with life experiences.

e) Evaluation

Students work on the evaluation questions to apply the concepts they have so that the teacher can observe student development as learning evaluation materials to the learning cycle model used.

Descriptive analysis of the results of the pre-test and post-test using IBM SPSS Statistics 22 can be seen in Table 1.2 as follows.

Table 2 Descriptive Analysis of Pre-test and Post-test Results

\begin{tabular}{|c|c|c|}
\hline Analysis & Pre-test & Post-test \\
\hline Mean & 55,63 & 78,94 \\
\hline Median & 54 & 75 \\
\hline Modus & 50 & 75 \\
\hline Std. Deviation & 8,11 & 5,53 \\
\hline Skewness & 0,42 & 0,91 \\
\hline Minimum & 43 & 72 \\
\hline Maximum & 72 & 90 \\
\hline
\end{tabular}


The pre-test and post-test values that have been tested for normality use the Kolmogrov-Smirnov analysis assisted by IBM SPSS Statistics 22 in Table 1.3.

Table 3 Normality of Pre-test and Post-test Result Data

\begin{tabular}{|c|c|c|}
\hline Deskriptif Statistik & Pre-test & Post-test \\
\hline N & 32 & 32 \\
\hline Normal parameters ${ }^{\text {a.b }}$ Mean & 55,63 & 78,94 \\
\hline Std. Deviation & 8,11 & 5,53 \\
\hline Test Statistic & 0,16 & 0,23 \\
\hline Asymp. Sig (2-tailed) & 0,03 & 0,00 \\
\hline
\end{tabular}

Based on the results of the Kolmogorov-Smirnov normality analysis, the pre-test has a count $(0.16)<\mathrm{K}_{\text {Table }}$ (0.24), while the Post-test has a Count $(0.23)<\mathrm{K}_{\text {Table }}(0.24)$. If the Test Statistic value is $>0.05$, then the data distribution is normal, so it can be concluded that the pre-test and post- test data are normally distributed. The distribution of scores obtained by students is processed with a Scatter Plot graph. Figure 1.3 below is a projection of the pre-test and post-test values then performed using the IBM SPSS Statistics 22 Scatter Plot.

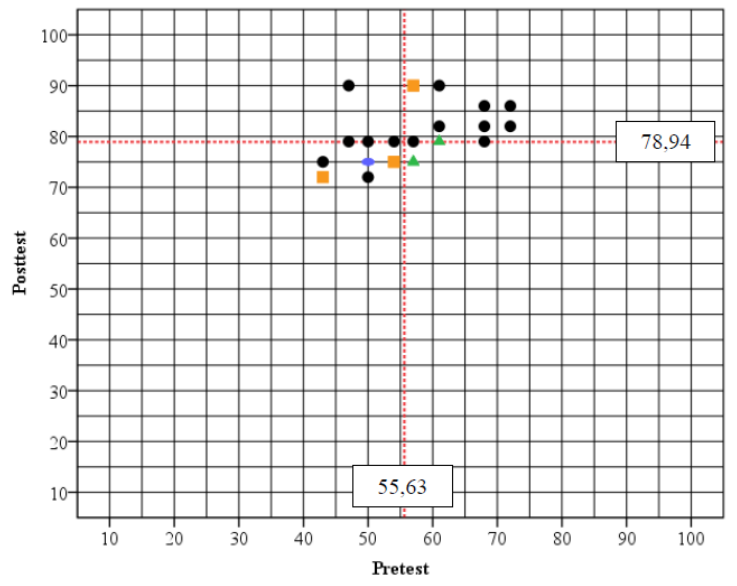

\section{Information:}

\section{Figure 1 Graph Scatter (Scatter Plot) of Pre-test and Post-test Value}

- $: 1$ student

- : 2 students

$\Delta: 3$ students

$0: 4$ students

Figure 1 shows that an average pre-test score of 55.63 with a standard deviation of 8.11 and an average posttest score of 78.94 with a standard deviation of 5.53 from a maximum score of 28 multiple choice questions. The score of pre-test score is lower because students do not understand the concepts of the solar system, do not learn and open existing learning resources. The post-test score is higher because students have been treated with solar system learning using the Learning Cycle 5E model. Thus it can be concluded that all pre-test scores have increased in post-test scores.

Pre-test and post-test values that have been normally distributed are then performed t-tests using two tailed t-test analysis assisted by IBM SPSS Statistics 22 . This test is used to determine the significance of differences before and after treatment given in Table 1.4. 
Table 4 Test the Difference between Pre-test and Post-test Results Data

\begin{tabular}{|c|c|c|c|c|c|c|c|}
\hline & Mean & Std. & 95\% Confid & of the & $t$ & $D f$ & Sig. \\
\hline & & & Lower & Upper & & & \\
\hline $\begin{array}{c}\text { Pair } 1 \\
\text { Post-test-Pre-test }\end{array}$ & 23,31 & 7,17 & 20,73 & 25,90 & 18,39 & 31 & 0,00 \\
\hline
\end{tabular}

Based on the results of paired sample t-test analysis, tcount of 18.39 and $\operatorname{sig}(p)=0.00<0.03$ indicates that there are differences in the pre-test and post-test values. The results of the two tailed t-test analysis can be concluded that there are differences in students' critical thinking skills before and after being given learning treatment using the $5 \mathrm{E}$ Learning Cycle model with higher results than before. The difference between the pre-test and post-test values has been proven by the t-test, then calculate the magnitude of the difference between the pre-test and post-test values using the d-effect size (d) analysis. Table 1.5 presents the results of the calculation of the impact strength test which includes d-effect size.

Table 5 Impact Strength Test

\begin{tabular}{|c|c|}
\hline Statistik Deskriptif & Nilai \\
\hline$d$-effect size & 3,42 \\
\hline
\end{tabular}

Based on the calculation, the d-effect size value is 3.42> Correct answers per item have increased differently. 1.00 (very high). The results of the d-effect size (d) analysis can be concluded that the magnitude of the difference Increased correct answers from pre-test and post-test seen between the pre-test and post-test values is very high.

in Figure 1.4.

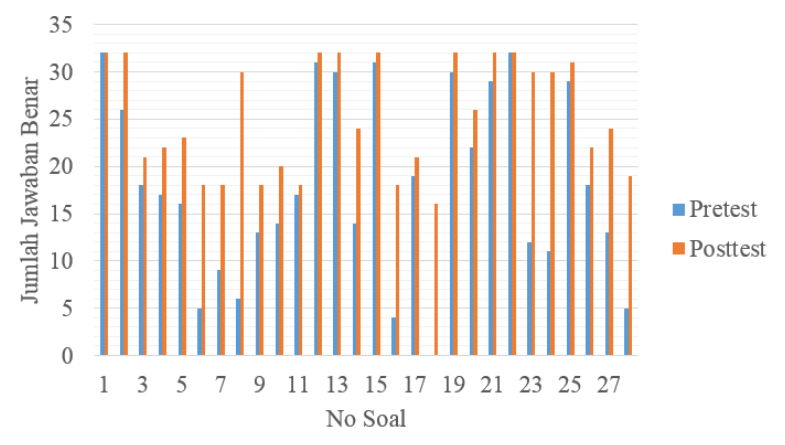

Figure 2 Graph of Number of Correct Answers per Item Problem

Based on Figure 2 can be seen an increase in the number of correct answers students on the pre-test and post-test per item. The highest increase occurred in problem number 8 which was 24 students, while the lowest increase in problem number 11 increased only one student.

\section{CONCLUSION}

Based on the results of research and discussion that has been presented previously, it can be concluded as (1)Science learning by applying the Learning Cycle 5E model to the solar system material is well implemented with an average percentage of $90.2 \%$ learning accomplishment, and (2) Increased critical thinking skills of Class VII I students of SMPN 1 Karangploso on the material of the 
Solar System by applying the Learning Cycle 5E model with an average d-effect of 3.42 which is included in the very high category, so it can be concluded that the students' critical thinking abilities have increased significantly. significant.

Based on the results of research and discussion that have been presented previously, then the following suggestions can be given. Teacher, learning Learning Cycle $5 \mathrm{E}$ on the material of the Solar System is learning that can be sensed by students in everyday life, teachers should provide homework that can be sensed through student experience. Other researchers, practice exercises to improve students' critical thinking should cover more than 7 indicators of critical thinking.

\section{REFERENCES}

[1] Abdussalam, Sulthoni, Munzil. (2018). Virtual Reality Solar System Media to Increase Retention Ability. Journal of Education: Theory, Research and Development, 3 (9), 1160-1167.

[2] Budiasih, E., Widarti, H.R. (2004). Application of the Learning Cycle Approach in Learning Chemistry Practicum Analysis Instrument Courses. Journal of learning education. Field.

[3] Ennis, R. (2011). The Nature of Critical Thinking: An Outline of Critical Thinking Dispositions and Abilities. Chichago: University of Illinois.

[4] Facione. (2013). Critical Thinking: What It Is and Why It Counts. Measured Reasons and The California Academic Press, Millbrae, CA.

[5] Fahim, M. \& Eslamdoost, S. (2014). Critical thinking: Frameworks and models for teaching. Journal English Language Teaching, 7 (7), p. 214-222, ISSN 19164742, E-ISSN 1916-4750.

[6] Fajaroh, F. \& Dasna, I W. (2007). Learning with a learning cycle model (learning cycle). Article. Department of Chemistry FMIPA UM.

[7] Mabsuthoh, N. (2010). The effect of the learning cycle learning model on physics learning outcomes on the concept of mass. Thesis (not published). Syarif Hidayatullah State Islamic University.
[8] Mahfuzah, Bina Aulia., Munzil., Utomo, Yudhi. (2018). Effectiveness of GDL (Guided Discovery Learning) and Problem Solving on CBC (Critical Thinking Skills) and HOTS (Higher Order Thingking Skills). Journal of Education: Theory, Research and Development, 3 (6), 739-744.

[9] Mertiarti, Rodhiallah. (2018). Development of Science Teaching Materials by Explicating the Nature of Science (NOS) and Thinking Critically on the Topics of the Solar System. Thesis, Natural Sciences Education Study Program, Faculty of Mathematics and Natural Sciences, State University of Malang.

[10] Minister of Education and Culture Regulations. (2016). Minister of Education and Culture Regulation Number 103 of 2014 concerning Learning in Basic Education and Secondary Education. Jakarta: Ministry of Education and Culture.

[11] Ramadhani, N. (2012). The Effect of the 5E Constructivist Learning Model on Learning Outcomes at Admiral Martadinata High School. Journal of Physical Education. 1 (1). 45-50.

[12] Saputra, Hendrik., Hidayat, Arif., Munzil. (2016). Profile of Critical Thinking Ability in Students of SMPN 7 Pasuruan. Proceedings of the UM Science Postgraduate Education Seminar, 1 (1), 943-949.

[13] Tuna, A. \& Kacar, A. (2013). The Effect Of 5E Learning Cycle Model In Teaching Trigonometry On Students' Academic Achievement And The Permanence Of Their Knowledge. International Journal on New Trends in Education and Their Implications. 4 (1). 73-87.

[14] Yulianti, Erni., Husna, I. Y. A., \& Susilowati. (2018). The Role of Inquiry-Based Interactive Demonstration Learning Model on VIII Grade Students' High Order Thinking Skills. Journal of Science Education Research, 2 (1), 35-38. 